\title{
Evolutionary Game Analysis on the Major Stakeholders in Disabled Accessible Tourism
}

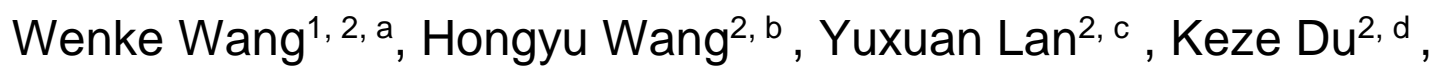 \\ Yue $\mathrm{Liu}^{2, \mathrm{e}}$ \\ 1 Visual Computing and Virtual Reality Key Laboratory of Sichuan Province, Sichuan Normal \\ University, Chengdu 610068, China \\ ${ }^{2}$ School of business, Sichuan Normal University, Chengdu 610068, China \\ afinance51@126.com, b1051418262@qq.com, '617816911@qq.com, \\ d872092549@qq.com, e389779549@qq.com
}

\begin{abstract}
As the state leaders are caring more about the people's livelihood problem, the disabled accessible tourism is getting more and more attention from domestic scholars and the public. Government departments and tourism enterprises are acknowledged as the important responsibilities which the disabled contact with directly in the development of the disabled tourism. Therefore, the article selects the two major stakeholders to construct the dynamic evolutionary game model: government and tourism enterprises, dissects the respective evolutionary stable strategy of these two parties and key influence factors in the process of game. The research results show that two stakeholders' final choices of strategy depend on the initial payoff matrix game and the influence of key parameters. The government should intensify the propaganda of encouragement policy and the publicity of tourism enterprises which implemented and supported the disabled tourism, reduce allowance for tourism industry as a whole. Tourism enterprises and tourist attractions should strengthen the personnel training on the professional services for the disabled.
\end{abstract}

Keywords: Disabled tourism; government; tourism enterprise; evolutionary game.

\section{Introduction}

Disabled Accessible Tourism, a travel business designed specifically for people with disabilities, was introduced to China in the early 20th century. In China, government departments and tourism enterprises are the two major parties which the disabled contact with directly in its long-term development. As profit-driven organizations, tourism enterprises want to gain profit from the newly thriving disabled tourism. Government departments, as a non-profit organization, also should ensure its financial operation when supports the disabled tourism. Therefore the disabled tourism will witness a game process that main stakeholders achieve mutual benefit and corporation successively through conflicts, balance and coordination. Thus this paper adopts an asymmetric revolutionary game model to analyze the stable state in the situation that the two stakeholders are mutually restricted and connected when developing the disabled tourism in the hope of providing theoretical basis and decision support to realize the disabled tourism and harmonize the relevant stakeholders.

\section{Research Process}

\subsection{Problem Research.}

According to the current development situation, government departments haven't made propaganda and incentive for the disabled tourism effective enough. Currently the disabled get most information of the accessible tourism from public welfare social organization's propaganda, while the propaganda of government departments' preferential policy to encourage the disabled tourism is rare. It is known that until now the government has not specially set up funds for the disabled people' travel. Some existing tourism funds for persons with disabilities are mainly initiated by public welfare social groups or together with some tourism enterprises. Still a small part of travel agencies volunteer to 
undertake activities of the disabled tourism out of social responsibility and in consideration of brand images. But in the long term, the high cost of organizing disabled tourism will curb those enterprises' incentives to carry out such activities. Therefore that such activities launched by tourism enterprises currently to achieve the disabled people's dream of travel are only few and during the travel the professional services for the mental or physical needs of the disabled have not been taken into consideration. Thus it can be understood that only relying on tourism enterprises' spontaneous actions can hardly the disabled tourism continue a long-term growth. It needs the cooperation from related stakeholders.

\subsection{Analysis of the revolutionary game model between government departments and tourism enterprises.}

Hypotheses of the model. Suppose the government departments either encourage or not the disabled tourism and the probability of encouragement is $y$, then other relevant hypotheses are as follows.(1)If government departments encourage the disabled tourism, they can gain reputational benefits (T) but has to pay encouraging cost $(\mathrm{G})$-subsidies for tourism enterprises. When tourism enterprises provide those services, the government can get exterior positive benefit of society (V).(2)If government departments don't encourage the disabled tourism and tourism enterprises still provide services, then government departments' reputation would get harmed (S); if the tourism enterprises don't provide services, then exterior negative benefit of society would happen (W) (V $\geq$ W ), and government departments would afford those social costs. Suppose tourism enterprises have two strategies: engaged in the disabled tourism or not and the possibility of the former is $\mathrm{x}$, then other relevant hypotheses are as follows.(1)The travel agencies which engaged in the business would gain direct economic benefit $\mathrm{R}$, direct cost $\mathrm{C}$, as well as government subsidies $\mathrm{G}$ if government departments encourage the tourism and reputation benefits (it is E1 when receives the government' encouragement, and E2 while not, E1 > E2).(2)The travel agencies which not engaged in the business would have reputation lose $\mathrm{J}$ (for it enjoys the government's subsidies but does not fulfill government's policy) and is not affected when government departments don't encourage the disabled tourism.

Construction of the model. According to the hypotheses for the model, the game matrix of government and tourism enterprises can be described as the table 1 .

Table 1 The evolutionary model of government and tourism enterprise

Tourism enterprise

Game-agents and their strategies

Engaged Not engaged
Encourage
$T+V-G, R+G+E 1-C$
$T-G, G-J$

Government
Discourage
$-S, R+E 2-C$
$-W, 0$

The replicated dynamic equations and evolutionary stable strategy of the model.

For tourism enterprises, the replicated dynamic equations of engaging in the disabled tourism is:

$F(x)=\frac{d x}{d t}=x(U x 1-\overline{U x})=x(1-x)[y(E 1-E 2+J)+R+E 2-C]$

Suppose $\mathrm{F}(\mathrm{x})=\mathrm{dx} / \mathrm{dt}=0$, the results can be:

$x 1^{*}=0, x 2^{*}=1, y^{*}=\frac{C-R-E 2}{E 1-E 2+J}$

According to the stability theorem of evolutionary game theory, when $\mathrm{F}^{\prime}\left(\mathrm{x}^{*}\right)<0, \mathrm{x}^{*}$ is the ESS. When $y=y^{*}, F(x)$ remains equal to 0 , that is to say, when the support from government departments to the disabled tourism is $\mathrm{y}^{*}$, any initial proportion of tourism enterprises engaged and not engaged in 
the tourism is stable. When $\mathrm{y}^{2}<\mathrm{y}^{*}$, on an interval of $(0,1)$ exists $\mathrm{F}^{\prime}(\mathrm{x})<0$ all the time, and simultaneously the replicated dynamic equation of tourism enterprises has two equilibrium points$\mathrm{x} 1^{*}=0, \mathrm{x} 2^{*}=1$. And because $\mathrm{F}^{\prime}(0)<0, \mathrm{~F}^{\prime}(1)>0$, thus when $\mathrm{y}<\mathrm{y}^{*}, \mathrm{x} 1^{*}=0$ is the only ESS in the game between tourism enterprises and government departments. That proves when government doesn't provide sufficient support for the disabled tourism, tourism enterprises would gradually tend to discard or not be engaged in the disabled tourism. In the same way, we can know when $\mathrm{y}<\mathrm{y}^{*}, \mathrm{x} 2 *=1$ is the only ESS in the whole game. That proves when government departments provide comprehensive support for the disabled tourism, the tourism enterprises would get more force to be engaged in the disabled tourism and thus benign interaction can be made between the two stakeholders.

For the government, replicated dynamic equation is:

$F(y)=y(U y 1-\overline{U y})=y(1-y)[x(V-W+S)+T-G+W]$

Suppose $\mathrm{F}(\mathrm{y})=\mathrm{dy} / \mathrm{dt}=0$, the results can be:

$y 1 * 0, y 2 * 1, x^{*}=\frac{G-W-T}{V-W+S}$

When $\mathrm{x}=\mathrm{x}^{*}$, any support from government departments for the tourism is stable. When $\mathrm{x}<\mathrm{x}^{*}$, $\mathrm{y} 1^{*}=0$ is the only ESS in the game between tourism enterprises and government departments. That proves when tourism enterprises are not keen on the disabled tourism, government departments also has no motivation to provide support. Therefore, the development of the disabled accessible tourism needs the cooperation of government and tourism enterprises. If the tourism enterprises keep indifferent towards the tourism, it would easily cause the government to overlook the issue that the the disabled people's needs of travel and entertainment haven't be meet, which would deteriorate the unfairness suffered by the disabled. When $\mathrm{x}>\mathrm{x}^{*}, \mathrm{y} 2^{*}=1$ is the only ESS in the whole game. That is to say, tourism enterprises are willing to provide services to the disabled and government departments would take all possible measures to promote the development of the disabled tourism, which would attain the Pareto Optimality stage by stage.

Analysis of the revolutionary game result. The trend of asymmetric game between the two stakeholders for the disabled tourism can be shown as Figure 1.

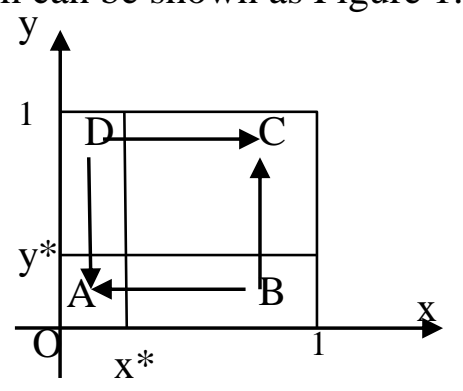

Figure 1 Phase graph of asymmetric game between government and tourism enterprises

According to the result of the asymmetric game between government and tourism enterprises, to make the system converge to equilibrium of Pareto optimality to the maximum possible extent, that is to say, to make the whole situation (encouraging, engaging) develop into a stable state, region $\mathrm{C}$ should take up a large part of the area while the region A the minor one. Therefore the Nash Equilibrium should get minimum value, namely $\left(x^{*}, \mathrm{y}^{*}\right)$ should of small value.

When $\mathrm{C}$ decreases and R, E2, E1, J increases, $\mathrm{y} *$ would decrease. Modern tourism enterprise is an interest-driven organization. Only when the benefit of new business outnumbers its cost and the increasing cost is affordable for the enterprises would tourism enterprises be engaged in the disabled tourism. Because the disabled tourism in our country currently is at the early stage and is not very popular, most disabled people who participate in travel and entertainment currently can ensure higher returns $\mathrm{R}$ to tourism enterprises. The increase $\mathrm{C}$ of the direct cost in the new business becomes the main obstacle which can only be adjusted by government departments. Government departments 
could organize public welfare social groups of the disabled tourism in many ways to assistant the tourism enterprises, such as providing professional guidance, sign language volunteers, etc., to reduce tourism enterprises' cost. In addition, government departments should intensify the propaganda for the tourism enterprises engaged in the tourism to give them more reputation. Simultaneously, government should give more notices of criticism to the enterprises which enjoy state subsidies but fail to provide corresponding services to exert pressure of damaging their reputation.

When the G decreases and T, W, V, S increase, $x^{*}$ would decrease. Government departments should reduce the allowance $\mathrm{G}$ for tourism industry as a whole and provide more specified subsidies. On the one hand, it can reduce government's cost of supporting the disabled tourism, on the other hand decrease the possibility that some tourism enterprises take advantage of the subsidies for immoral profit and prevent their motivation of nonfeasance. Simultaneously, government departments should intensify its publicity of preferential policies and subsidies, which would encourage more tourism enterprises to participate in the disabled tourism and also expand their influence and gain more reputation benefits T. For the situation that some tourism enterprises have provided business of the disabled tourism while government departments give no help, public opinion surveillance should be adopted to supervise and condemn that phenomenon, and thus the government departments would get a reputation loss S. Government's attitudes towards the tourism basically depends on its perception of the issue that the disabled people's spiritual needs of travel and entertainment haven been met. On the one hand, government departments should carry out in-depth social survey to make clear the potential threat (W) for the whole society posed by the existence of the issue. On the other hand, government should recognize that the realization of the disabled people's traveling dream can not only solve the social issue, but promote the development of the tourism industry and social economy and bring much benefit $(\mathrm{V})$ for the government in multiple aspects.

\section{Summary}

The paper mainly discusses the strategy evolution process of the disabled tourism between government departments and tourism enterprises and the construction of its stable state with current systems and developing status of tourism market, and obtains valuable conclusions:(1) government departments should actively strengthen the publicity of the disabled tourism concept, and in a larger scope encourage and publicize the tourism enterprises engaged in the tourism and proactively provide subsidies to those organizations. Except financial support, government should also give more "technological" support to tourism enterprises, for example, free staff training. (2) Tourism enterprises should not only pay attention to their own interests, but also fulfill their corporate social responsibility. On the one hand, tourism enterprises should improve their professional quality and attach importance to their service quality to meet the special needs of disabled people; On the other hand, the tourism enterprises should further merge the disabled tourism business with existing business to make full use of existing enterprise resources and by many ways reduce increasing cost of the new business. Those conclusions can further promote the development of the disabled tourism market.

\section{Acknowledgement}

Supported by the Philosophy and Social Sciences Program of Sichuan Province (No. SC15B071), Supported by the Program of the Visual Computing and Virtual Reality Key Laboratory of Sichuan Province (No.KJ201420), Supported by the Program of the Department of Education of Sichuan Province(No.14SB0022), Supported by the Sichuan provincial innovation and entrepreneurship students Training Program (201410636045, 201510636087). 


\section{References}

[1] Trinidad Domínguez Vila, Simon Darcy, Elisa Alén González. Competing for the disability tourism market - A comparative exploration of the factors of accessible tourism competitiveness in Spain and Australia[ J]. Tourism Management, 2015,47(4): 261-272.

[2] Li Xuena. How to develop the disabled tourism market for scenic spots and travel agencies [J]. Brand, 2015(1): 22-23.

[3] Zhao Liming, Chen Zhezhi, Liu Jiayue. Evolutionary game theory between local government and tourism enterprises in the context of a low-carbon economy [J]. Tourism Tribune, 2015, 30(1): 72-82.

[4]Huang Xiaoxing, $\mathrm{Hu}$ Zhenpeng, Fu Chun et al. Evolutionary game analysis on the main stakeholders in ecotourism[J]. Ecological Economy, 2015, 31(1): 142-171. 